\title{
EL DERECHO DE REUNIÓN Y MANIFESTACIÓN EN EL NUEVO MARCO REGULATORIO DE LA LEY DE PROTECCIÓN DE SEGURIDAD CIUDADANA LO 4/2015 DE 30 DE MARZO
}

\author{
Marcos Francisco Massó Garrote
}

doi: 10.18543/ed-64(2)-2016pp101-126

SUMARIO: I. INTRODUCCIÓN: ORIGEN Y ANTECEDENTES DE LA NUEVA LO 4/2015 de 30 de Marzo de Protección de Seguridad CiUdadANA (LPSC). II. APROXIMACIÓN CONCEPTUAL AL DERECHO DE REUNIÓN Y MANIFESTACIÓN EN LA DOCTRINA Y JURISPRUDENCIA CONSTITUCIONAL. NATURALEZA JURÍDICA Y DIMENSIÓN POLÍTICA DEMOCRÁTICA. III. CONTENIDO Y EJERCICIO DEL DERECHO. A. Modalidades y clases del Derecho de Reunión. 1. Reuniones en lugares cerrados. 2. Las Reuniones en lugares abiertos de tránsito público: el derecho de manifestación. a. La comunicación previa de la autoridad gubernativa. b. Pacífica y sin armas. B. Los límites al ejercicio del derecho de reunión. 1. El Concepto de alteración del orden público. 2. Los límites derivados del ejercicio de otros derechos: el caso especial de la libre circulación de personas. 3. Los límites derivados de la integridad moral de las personas. 4 Los límites inherentes al ejercicio del derecho de petición y la autonomía de las Cortes. 5. Derecho de reunión versus Derecho de participación política. 6. El uso de uniformes paramilitares de los asistentes. IV. LAS ACTUACIONES DE LA LO 4/2015 LPSC PARA EL MANTENIMIENTO Y RESTABLECIMIENTO DE LA SEGURIDAD CIUDADANA EN REUNIONES Y MANIFESTACIONES. IV. LAS POTESTADES ESPECIALES DE POLICÍA ADMINISTRATIVA DE SEGURIDAD EN EL EJERCICIO DEL DERECHO DE REUNIÓN Y MANIFESTACIÓN Y EL NUEVO RÉGIMEN SANCIONADOR. A. Los sujetos responsables y la regulación de las nuevas infracciones 
muy graves. B. La nueva regulación y supuestos de infracciones graves. C. El nuevo catálogo de infracciones leves. V. CONCLUSIONES.

\section{INTRODUCCIÓN: ORIGEN Y ANTECEDENTES DE LA NUEVA LO 4/2015 DE PROTECCIÓN DE SEGURIDAD CIUDADANA}

La justificación de la nueva LO 4/2015 del 30 de marzo, de protección de seguridad ciudadana (LPSC) que entró en vigor el 1 de abril de este año, a juicio del legislador tiene su base en la demanda creciente en torno al concepto de seguridad difícilmente demostrable. Sin embargo, no aparecen dentro de la opinión pública, un preocupación tal que amerite una reforma de este calado que implica un control estricto del espacio público, pues de acuerdo con las encuestas apenas el $0.2 \%$ de la población considera que la inseguridad es el principal problema del país. Las modificaciones que lleva aparejada la ley actual, con relación a la ley anterior LO 1/1992 del 21 de febrero sobre Protección de la Seguridad Ciudadana, suponen una restricción en nuestras libertades sin precedentes en toda la etapa democrática, pues afectan especialmente al derecho de manifestación, al derecho de reunión, a la libertad de expresión, al derecho de información, a la libertad personal y al derecho de huelga. Con esta Ley, llamada popularmente como «Ley Mordaza» se ha desplegado desde el Poder Político un incremento de la respuesta penal y sancionadora por razones de seguridad. La realidad es que esta norma surge en un contexto de evidentes tensiones sociales y resulta imposible no relacionar estas iniciativas con el malestar social existente ante la precarización de las relaciones laborales y el incremento del desempleo, así como ante los recortes en sanidad, educación, justicia o prestaciones sociales. El desmantelamiento del Estado Social está provocando una reacción de defensa de sus principios básicos entre numerosos sectores de la ciudadanía.

Debe señalarse, que este descontento social se ha canalizado hacia las más variadas formas de protesta, las cuales han tenido como denominador común el carácter esencialmente pacífico de las mismas. A pesar del gran número de manifestaciones y reuniones convocadas en los últimos tiempos, sólo se han producido alteraciones del orden público en un porcentaje irrelevante. Precisamente por ello, no puede sorprender que las restricciones legales no se dirijan de manera directa contra las alteraciones del orden público, sino contra el ejercicio intenso y democrático del ciudadano de su derecho a manifestarse libremente como forma de expresar su discrepancia. Por ello, el espíritu de la reforma, suavizado eso sí desde su proyecto original hasta su redacción final, a causa de los dictámenes emanados del Consejo del Poder Judicial y del Consejo de Estado, viene a sancionar de manera especial determinadas formas reivindicativas críticas con el poder político, lo que supone 
a nuestro juicio la puesta en cuestión de propio Estado democrático, al restringir uno de sus derechos más básicos como es el derecho de manifestación. La idoneidad de las medidas contempladas en la ley implican importantes injerencias al derecho de reunión y manifestación como analizaré a continuación que afectan tanto los principios de idoneidad y proporcionalidad, lo que ha provocado que tengamos una ley que amplía en gran medida el margen de discrecionalidad del poder público y de la autoridad, en la adopción de medidas que pueden restringir el derecho de reunión y manifestación, lo que se traduce en un coste para los ciudadanos en el ejercicio de sus derechos y libertades, que no parece en modo alguno equilibrado por los beneficios concretos que resultan del orden público. A pesar de que la ley afecta un gran contenido de medidas de seguridad ciudadana me centraré en este artículo en aquellas que afectan o inciden en el ejercicio democrático del derecho fundamental de reunión y manifestación.

\section{APROXIMACIÓN CONCEPTUAL AL DERECHO DE REUNIÓN Y MANIFESTACIÓN EN LA DOCTRINA Y JURISPRUDENCIA CONSTITUCIONAL. NATURALEZA JURÍDICA Y DIMENSIÓN POLÍTICA DEMOCRÁTICA}

El derecho de reunión es uno de los derechos fundamentales más relevantes en un Estado de naturaleza democrática, pues tiene que ver con la libertad de los ciudadanos de congregarse con otros, según sus propias preferencias, cuyos propósitos pueden ser políticos, económicos, sociales, culturales o de cualquier otra índole. A tal respecto, su contenido esencial no es otro que el de reconocer el carácter gregario que opera como uno de los rasgos distintivos de la especie humana. Sin embargo, es evidente que la cobertura conceptual del derecho de reunión está provista de mayor amplitud, toda vez que el mismo es catalogado, simultáneamente como un derecho político y como un instrumento eficaz para el ejercicio de otros derechos fundamentales, como es el caso de la libertad de expresión ${ }^{1}$ y el derecho de asociación. Como ha tenido ocasión el Tribunal Constitucional de afirmar este principio es cauce del principio democrático participativo. Su naturaleza política es puesta de manifiesto por la doctrina más relevante ${ }^{2}$. El TC parece consolidar en toda su

${ }^{1}$ En ese sentido, Ruiz Robledo cataloga al derecho de reunión como un derecho híbrido de los derechos de libertad ideológica y de asociación. Cfr. RuIz RoBledo, Agustín, Compendio de Derecho Constitucional español (Valencia: Tirant lo Blanch, 2006), 314.

${ }_{2}$ A propósito de esta cualidad, el propio TC, en la referida sentencia 85/88 califica al derecho de reunión como «un cauce del principio democrático participativo», mientras que Torres Muro lo cataloga como uno de los elementos básicos de toda sociedad libre y democrática. Cfr. TORRES Muro, Ignacio, El derecho de reunión y manifestación (Ma- 
doctrina esta visión al definir en una de sus últimas sentencias, el derecho de reunión como «aquella manifestación colectiva de la libertad de expresión, como un derecho individual en cuanto a sus titulares y colectivos en su ejercicio, que opera a modo de técnica instrumental puesta al servicio del intercambio o exposición de ideas, la defensa de intereses, constituyendo, por lo tanto, un cauce del principio democrático ${ }^{3}$.

La doctrina también es unánime a la hora de considerar el derecho de reunión con una técnica de acción política directa, al servicio de fines que extravasan el puro contenido del derecho ${ }^{4}$. El derecho de reunión como dere-

drid: Civitas, 1991), 7. Por otro lado, el jurista costarricense Manrique Jiménez Meza plantea que: «La nueva dimensión constitucional de la democracia está ligada al eficaz derecho ciudadano de participación en asuntos de interés público, con técnicas instrumentales para su ejecución y defensa, al amparo de los ordenamientos jurídicos compuestos del derecho escrito y no escrito». Cfr. JIMÉnEz MEZA, Manrique, Derecho constitucional y administrativo (3. ${ }^{a}$ ed., San José: Editorial Jurídica Continental, 2005), 201. Siguiendo este razonamiento, es indudable que, más que cualquier otro derecho fundamental, el derecho de reunión se conecta idóneamente con los requerimientos que exige la creación de un sistema democrático participativo, por lo que puede decirse enfáticamente que el orden democrático de las sociedades actuales no puede existir sin una adecuada proyección legislativa y un verdadero ejercicio del derecho de reunión, coincidiendo así con Solozábal, quien claramente expresa que sin derecho de reunión no habría democracia. Cfr. SolozÁBAL ECHAVARRÍA, Juan José, «La configuración constitucional del derecho de reunión», Anuario Parlamento y Constitución 5 (2001): 106.

${ }^{3}$ Entre otras, STC 170/2008 de 14 de diciembre, FJ.3, que reitera en las SSTC 66/1995 de 8 de mayo, FJ.3, 196/2002 de 28 de octubre, FJ.4 y la 301/2006, de 23 de octubre, FJ.2.

${ }^{4}$ Afirma Santamaría Pastor que: «...difícilmente podría concebirse un sistema democrático sin el reconocimiento de este derecho fundamental, el cual además de hacer posible el intercambio de ideas y opiniones, permite al conjunto social influir en la toma de decisiones del poder del poder político», SANTAMARÍA PASTOR, Juan Alfonso, «El artículo 21», en Comentarios a la Constitución, dirigido por Fernando Garrido Falla (Madrid: Civitas, 1985), 412. González Rivas califica tal derecho como «un auténtico Derecho público subjetivo y afirma que presenta un contenido positivo como libertad instrumental del principio democrático participativo y un contenido obligacional en la medida en que compete a los servicios de orden público la protección positiva del referido derecho». GonZÁlez Rivas, Juan José, El derecho de reunión y manifestación (Madrid: Civitas, 1992), 15 y VIDAL MARín, Tomás, «El Derecho de reunión y manifestación», Revista Parlamento y Constitución 1 (1990): 266. Esta dimensión política, objetivo e institucional es la que resalta con toda razón Torres Muro cuando señala al derecho de reunión como el más básico de toda sociedad democrática «cuyo ejercicio puede tener lugar, bien únicamente convocando y promoviendo la reunión o manifestación de que se trate, o bien solamente asistiendo a las mismas, sin perjuicio, claro está, de que determinadas personas ejercitarán la libertad de reunión llevando a cabo ambas actividades». Véase TORRES Muro, El derecho de reunión..., 24. En consecuencia señala SORIANO DíAZ, «El Estado tiene la obligación de preparar los medios coadyuvantes al ejercicio de este derecho de 
cho público subjetivo individual de ejercicio colectivo y cauce del principio democrático tiene su naturaleza más básica en la extensión de la libertad de expresión como uno de los elementos más básicos de toda sociedad libre y democrática. Se trata sin duda de un derecho fundamental de autonomía propia, pero de indudable carácter instrumental respecto de otros derechos fundamentales como el derecho de asociación, el derecho de participación política, la libertad sindical, pero sobre todo de la libertad de expresión. De hecho, para muchos grupos sociales, señala la STC 301/2006, este derecho es en la práctica, uno de los pocos medios de los que disponen para poder expresar públicamente sus ideas y reivindicaciones ${ }^{5}$. Siguiendo esta línea argumental el TEDH subraya que la protección de las opiniones y de la libertad de expresión constituye uno de los objetivos de la libertad de cualquier democracia y constituye uno de los fines y fundamentos de la libertad de reunión ${ }^{6}$. Recuerda el TEDH en el asunto Guneri que «la libertad de reunión y el derecho a expresar puntos de vista a través de ella, están entre los valores primordiales de una sociedad democrática. La esencia de la democracia es su capacidad de resolver los problemas por medio de debates abiertos. Las medidas restrictivas de naturaleza preventiva para suprimir la libertad de reunión y expresión, hacen un flaco favor a la democracia y a menudo la ponen en peligro. En una sociedad democrática basada en el Estado de Derecho, se debe ofrecer una adecuada oportunidad de expresión de las ideas políticas que discutan un orden existente y cuya realización se proponga por medios pacíficos, a través del ejercicio del derecho de reunión». La protección de la libertad de expresión de opiniones personales, es uno de los objetivos de la libertad de reunión pacífica. Por tanto, la libertad de expresión encuentra un claro vehículo de ejercicio a través de la libertad de reunión, que se convierte así en un cauce, entre otros, para el ejercicio de los derechos políticos de quienes intervienen en la manifestación.

cara a los participantes en el acto de la reunión, y de otra parte, ha de establecerse las medidas de seguridad necesarias para la tutela de derechos de terceros que podrá ser afectada por la celebración de la reunión». Véase SORIANO DíAz, Ramón, «Artículo 21. Derecho de Reunión», Comentarios a la Constitución de 1978, dirigidos por Oscar Alzaga Villaamil (Madrid: Edersa, 1984), 568.

5 SSTC 301/2006, de 23 de Octubre, FJ.2 y 195/2003, de 27 de Octubre FJ.3.

${ }^{6}$ STEDH caso Stannkov, de 2 de octubre del 2001, numeral 85 o también que «la libertad de expresión constituye uno de los medios principales que permite asegurar el disfrute efectivo del derecho reunión y de asociación» (STEDH caso Rekvenyi, de 20 de mayo de 1999, numeral 58). 


\section{CONTENIDO Y EJERCICIO DEL DERECHO}

\section{A. Modalidades y clases del derecho de reunión}

\section{Reuniones en lugares cerrados}

La celebración de reuniones en lugares cerrados carece de peculiaridades procedimentales y afectan en muy escasa medida al ejercicio del derecho fundamental. Solo la LODR 9/1983 se limita a facultar a los organizadores y promotores de las mismas para solicitar la presencia de delegados de la autoridad gubernativa (art.6). Su función es puramente preventiva y se orienta en la finalidad de ayudar a los organizadores a mantener el buen orden de la reunión y, en caso necesario, poder ponerse en contacto con la autoridad para adoptar medidas adicionales de seguridad. En todo caso, los delegados no podrán intervenir en las discusiones o debates ni harán uso de la palabra para advertir o corregir a los participantes todo ello sin perjuicio de lo establecido en el artículo 7 de la LECRIM a efectos de la Comisión de eventuales delitos. $\mathrm{N} .^{\circ}$ debe confundirse la no exigencia de autorización previa para reunirse con la autorización previa del propietario de un local, de titularidad pública o privada, para su uso como lugar de reunión (STC/91/1983, de 7 de noviembre, FJ.2).

Como apunta Gavara de Cara, el texto del artículo 6 permite deducir que esta modalidad de reunión debe ser forzosamente pública y con carácter abierto, ya que, en caso contrario, las reuniones de este tipo se encontrarían excluidas del ámbito de la LODR ${ }^{7}$. Con todo, las facultades de suspensión y disolución de reuniones y manifestaciones por parte de la autoridad pública se extienden también a las reuniones en lugar cerrado. Las reuniones en lugares cerrados que impliquen la utilización de dependencias públicas o las celebradas, en general en el ámbito laboral, se encuentran sometidas al correspondiente permiso para dicha utilización. En realidad, la autorización no se exige para la celebración de la reunión en sí sino, por ejemplo, en el ámbito público, para la utilización de unas dependencias destinadas de modo preferente a la prestación de un servicio público ${ }^{8}$. El fundamento no es otro que dichas reuniones pueden afectar al funcionamiento de la actividad de que se trate y requieren la colaboración de la empresa privada o de las Administraciones Públicas para llevarlas a cabo. El conflicto entre derecho de reunión y manifestación y el derecho de propiedad privada se resuelve, generalmente a favor del derecho de propiedad con la tipificación de determinadas

${ }^{7}$ GAVARA DE CARA, Juan Carlos, El sistema de organización y ejercicio del derecho de reunión y manifestación (Madrid: Mc. Graw-Hill, 1997), 78.

${ }^{8}$ STC 29/200 de 31 de enero, FJ.3 
conductas como las constitutivas de allanamiento de morada o los desórdenes públicos.

\section{Las reuniones en lugares abiertos de tránsito público: las manifestaciones}

Se incluyen aquí en esta modalidad tanto las reuniones que se celebren en lugares de tránsito público como las manifestaciones, es decir las reuniones de carácter dinámico en las que se produce el desplazamiento de personas en un lugar de tránsito público. Sobre estas reuniones ha escrito Santamaría Pastor que su ámbito es más estricto que el clásico concepto de reuniones al aire libre, en cuanto remite a un dato puramente jurídico, o sea, si el lugar en cuestión está o . $^{\circ}$ destinado normalmente al tránsito de personas o vehículos. En consecuencia, las reuniones celebradas al aire libre, pero en lugar no abierto al tránsito público (por ejemplo, un campo de futbol) comprende las celebradas en locales públicos descubiertos o los espacios abiertos como un campo acotado, equivalente por tanto a las concentraciones ${ }^{9}$. Las manifestaciones no han de entenderse como sinónimo de reuniones en lugar abierto, pues entonces las reuniones en lugares de tránsito público serían también manifestaciones, sino como reuniones en marcha, estos es las procesiones cívicas, séquitos y cortejos como en la Ley Alemana de 1880 o los Aufzüge ${ }^{10}$. Tanto unas como otras son siempre públicas. En cuanto a los requisitos para poder celebrar este tipo de reunión, el artículo 8 señala los siguientes:

\section{a. La Comunicación previa a la autoridad gubernativa.}

$\mathrm{Al}$ realizarse estas reuniones en un determinado lugar en la que el riesgo para la libertad de los manifestantes y los derechos y bienes básicos de terceros imponen su comunicación previa a la autoridad gubernativa a efectos de la adopción por su parte de las medidas pertinentes ${ }^{11}$. Pero esta intervención administrativa no puede consistir en una autorización que impida cualquier tipo de reunión, lo cual deberá hacer imposible una comprensión de la comunicación que la equipare a la solicitud de autorización, como resulta, de la exclusión constitucional expresa de la autorización. La comunicación previa se refiere a los siguientes términos: se trata de un escrito dirigido a la autoridad gubernativa con una antelación mínima de 10 días y 30 como máximo.

9 Véase SANTAmaría PAStor, J.A., «El artículo 21», 416.

10 Véase SolozÁBAl EcheVARRÍA, J.J., «La configuración constitucional del derecho de reunión», 20.

${ }^{11}$ La finalidad no es otra señala el TC en su STC 59/1990 de 29 de marzo de posibilitar tanto el ejercicio en libertad del derecho de los manifestantes como la protección de los derechos y bienes de titularidad de terceros. 
No obstante, y únicamente cuando existan circunstancias extraordinarias y graves, nuestro ordenamiento jurídico admite que dicha comunicación pueda hacerse en un plazo inferior a las 24 horas (STS de 12 de diciembre de 1994). La amplitud de los plazos para efectuar en las convocatorias ordinarias, guarda estrecha relación con el control judicial de la posible prohibición y con la finalidad que cumple la comunicación que no es otra que la autoridad gubernativa valore adecuadamente las condiciones de ejercicio de ese derecho y adopte las medidas necesarias tanto para posibilitar su ejercicio como para proteger los derechos y bienes de titularidad de terceros ${ }^{12}$. En efecto, como no podría de ser de otra manera, la posible intervención de la autoridad gubernativa no es para controlar y en su caso prohibir sino de garantizar y respetar para que el derecho de reunión se realice en las mejores condiciones y respeto para los bienes y las personas afectadas. Los posibles excesos que pueda incurrir la autoridad gubernativa en el ejercicio de sus potestades son susceptibles de control judicial. El incumplimiento de dichos requisitos constituye un ilícito administrativo de un requisito necesario por ser constitucional. En consecuencia, si falta la autoridad administrativa puede prohibirla cuando circunstancialmente tenga conocimiento oficioso de la misma y siempre disolverá una vez iniciada, pero rechazamos la tesis de García Escudero y Pendás ${ }^{13}$ que han defendido que la falta de comunicación su consecuencia inmediata es la suspensión o disolución cuando la Administración no pudiera disponer de los medios oportunos para salvaguardar el orden público, incluso ni siquiera eso cuando la manifestación cumpla con los requisitos materiales de la misma ${ }^{14}$. También el TC insiste en la STC 66/1995 en que solo se puede prohibir una reunión cuando existan razones fundadas que

12 Véase en este sentido la opinión de FAnLo Loras, A., «El derecho de Reunión, Manifestación y Asociación: especial referencia a los Partidos Políticos y Colegios Profesionales» en el libro colectivo Libertades Públicas y Derecho Administrativo, Cuadernos de Derecho Judicial, 20 (Madrid: Ed. Consejo General del Poder Judicial, 1994), 45.

${ }^{13}$ García-Escudero Márquez, Piedad y Pendás García, Benigno, «Régimen jurídico del derecho de reunión», Revista de Derecho Politico 22, 1986: 206.

${ }_{14}$ Señala Vidal Marín que la comunicación previa de la reunión debe hacerse por escrito y su contenido ha de ser congruente con la finalidad de la misma, es decir, debe comprender los datos estrictamente necesarios para que la autoridad gubernativa pueda tomar las medidas pertinentes pero para proteger el derecho de reunión y para evitar incidencia negativa, VIDAL MARín, «El derecho de reunión y manifestación», Parlamento y Constitución, 1, 1997, 269. En esta misma línea López González señala que la ausencia de este requisito concede lógicamente a la autoridad gubernativa la posibilidad de prohibir el ejercicio de este derecho. Ahora bien, esta posibilidad hay que entenderla referida a aquellos casos en los cuales la falta de comunicación conlleva la imposibilidad de que la Administración adopte medidas necesarias para proteger el orden público. LóPEZ GoNZÁLEZ, J. L., El derecho de reunión y manifestación en el ordenamiento constitucional (Madrid: Ministerio de Justicia, 1995), 45. Para Pérez Castaño esta prohibición no es una 
permitan concluir que se producirá una situación de desorden material entendiendo por tal aquel que impide el normal desarrollo de la convivencia ciudadana en lo que afecta a la integración física o moral de las personas o la integridad de bienes públicos o privados, siempre y cuando se trate de un desorden material que ponga en peligro la integridad de bienes públicos o privados, siempre y cuando se trate de un desorden material que ponga en peligro la integridad de personas o de bienes ${ }^{15}$.

\section{b. Pacifica y sin armas.}

Otro de los elementos que configura el ejercicio del derecho de reunión son los elementos constitucionales del artículo 21 cuya exigencia determina que la reunión debe ser pacífica y sin armas. Desde el punto de vista penal, debemos entender por armas aquel objeto contundente o peligroso preparado para la alteración de la paz pública o aquel instrumento cuya naturaleza le hace objetivamente adecuado para herir a las personas o dañar a las cosas, destinándoles intencionalmente sus portadores a tal propósito. Reunión pacífica es aquella cuyos promotores excluyen comportamientos violentos en su transcurso, garantizándose a través de la organización correspondiente un desarrollo en paz de la misma, de modo que durante su celebración no se va a instigar a la comisión de un delito o de desórdenes ni tolerarse su realización. Naturalmente el carácter pacífico de la reunión no cuestiona el hecho de que haya incidentes, aunque sean graves, causados por una minoría o por un colectivo antisistema, de manera que la protección del ejercicio constitucional de un derecho no puede quedar disponible al designio antidemocrático de una minoría. No obstante, la protección constitucional de este derecho fundamental no excluye la responsabilidad penal de quienes sean sus autores en los términos previstos en los artículos correspondientes del Código Penal arts. 513 y 514. La prohibición de portar armas se incumple cuando lo hace un número significativo de asistentes, de modo que quienes las llevan sean irreductibles para el propio servicio de orden de la concentración. En cuanto al término «sin armas» podemos también resaltar la opinión de Torres Muro

obligación para la autoridad, sino una posibilidad. PéRez CASTAÑo, Domingo, Régimen jurídico del derecho de reunión (Madrid: Ministerio del Interior, 1997), 345.

${ }^{15}$ En todo caso la decisión tiene que ser motivada sobre estos argumentos y no solo sobre la falta de comunicación previa pues tal y como señalan Ruiz Piñero y Sainz Fernández «las posibilidades de prohibir una manifestación son reducidas: únicamente se podrá producir esa prohibición cuando se ocasione una total obstrucción de las calles que desemboque en un colapso circulatoria durante un periodo de tiempo prolongado, de forma que se provoque la inmovilización de vehículos y se impida el acceso a determinadas zonas o barrios de la ciudad por la imposibilidad de habilitar vías alternativas» RUIz PIÑEIRO, F.L. y SAIZ FernandeZ, R, El derecho de reunión y Manifestación (Cizur Menor: Ed. Aranzadi, 2010), 51. 
que siguiendo a Pace concluye que «atendiendo al sentido último de la falta de reconocimiento del derecho a reunirse con armas, que parece ser el de evitar que se añada a la presencia de numerosas personas el riesgo de que éstas lleven objetos con los que agredir, cabe que serán armas a los efectos de calificar al reunión de «armada» solamente aquellos objetos que tengan por objetivo atacar o defenderse violentamente de las demás personas. En síntesis sería reunión con armas aquella en la que la mayoría de los participantes con el consentimiento de los organizadores llevase objetos cuyo único objetivo fuera de ser utilizados para atacar o defenderse ${ }^{16}$. En definitiva, la finalidad constitucional de la misma no es otra aquellas reuniones que tengan por objeto o al menos muchas posibilidades de alterar la vida normal ciudadana de una manera violenta. No obstante, por concepto de «arma» no puede entenderse cualquier objeto que sea susceptible de causar un daño físico a otra persona puesto que entonces pocos objetos podrían escapar de esta consideración. A nuestro juicio, por arma hay que entender todo objeto cuyo uso normal sea atacar a otro o defenderse (pistolas, navajas, cadenas, etc... $)^{17}$. En

16 Véase Torres Muro, El derecho de reunión..., 65.

17 Si bien como afirman García-Escudero y Pendás, «es evidente que tal circunstancia tendrá que determinarse en cada caso, siendo preciso acudir a criterios valorativos, es decir, debe ponderarse adecuadamente, el número de asistentes con armas, la calidad de estas, la actitud de los restantes concurrentes, el conocimiento o el control del hecho por los organizadores, etc.)», García-Escudero Márquez y Pendás García, «Régimen jurídico del derecho de reunión», 208. González Pérez, refiere como ilícitas aquellas a las que se porten, siguiendo el Código Penal, Art. 514.1 del C.P. «armas, artefactos explosivos u objetos contundentes o de cualquier otro medio peligroso». GonZÁlez PÉrEZ, J., Derecho de reunión y manifestación (Madrid: Ed. Civitas, Madrid, 2002), 34. En este sentido el concepto de reunión armada nos sitúa ante el tipo definido en el artículo 167.2 del CP que considera ilícitas las reuniones o manifestaciones en el sentido señalado. El tipo delictivo se realiza por la tenencia de armas en sentido estricto, esto es, aquellos objetos cuyo uso específico sea atacar o defenderse violentamente de las demás personas (armas de fuego pero también otros objetos contundentes como porras, barras de hierro, piedras, etc...). Según señalan Ruiz Piñero y Saiz Hernández (2010, p.42), bastaría un día de lluvia para que los paraguas de los manifestantes sirvieran de elemento definidor del tipo delictivo, pues un paraguas, además de proteger de la lluvia, puede ser utilizado como objeto agresivo.

Tomás Vidal afirma en su trabajo que por reunión pacífica hay que entender la que no es violenta, señalando que será pacífica aquélla que no tenga por finalidad la comisión de actos violentos o bien aquella en cuyo desarrollo se producen actos de violencia significativos para a continuación examinar el tema de las reuniones que pueden por objeto la defensa o apología de las acciones violentas, entiende que la defensa de tales acciones no confiere a una reunión el carácter de violenta, puesto que es perfectamente factible que estas reuniones se desarrollen de una manera pacífica. Ahora bien, otra cosa es que la apología de acciones violentas constituya ilícito penal, en cuyo caso, tales reuniones no podrán ser objeto de tutela jurídica (VIDAL MARTíN, «El derecho de reunión y manifesta- 
cualquier caso del concepto pacífico se desprende que para calificar una reunión de no pacífica es necesario que los actos de violencia se produzcan por un número notable de asistentes.

\section{B. Los límites al ejercicio del derecho de reunión}

\section{El concepto de alteración del orden público}

El artículo 21.2 de la CE faculta a la autoridad gubernativa a prohibir el ejercicio del derecho de reunión cuando existan razones fundadas de alteración del orden público con peligro para las personas o bienes, estableciendo así expresamente un límite al ejercicio del derecho. Por su parte y congruentemente con este mandato constitucional, la LODR habilita a la autoridad gubernativa para suspender y disolver las reuniones y manifestaciones en las que concurran estas circunstancias.

Por lo que se refiere a la limitación del derecho de reunión el TC ha recordado que dicho derecho no es un derecho absoluto o ilimitado, sino que, al igual que los demás derechos fundamentales, tiene sus límites, entre los que se encuentra tanto el específicamente previsto en el artículo 21.2 como aquellos otros que vienen impuestos por la necesidad de evitar que un ejercicio extralimitado de ese derecho pueda entrar en colisión con otros valores constitucionales ${ }^{18}$. El propio Convenio de Derechos Humanos en su artículo 11.2 prevé la posibilidad de adoptar las medidas restrictivas que previstas en la ley, sean necesarias, en una sociedad democrática, para la seguridad nacional, la seguridad pública, la defensa del orden y la prevención del delito, la protección de la salud o de la moral, o la protección de los derechos y libertades ajenos y en este sentido el TC en su STC 195/2003, de 27 de Octubre, FJ.4 siguiendo la doctrina del TEDH (STEDH caso Cisse, de 9 de abril del 2002) consideró proporcionada la orden gubernativa de evacuación de una iglesia ante una reunión pacífica en sí misma no perturbadora del orden público y del derecho de culto, en la que, sin embargo, el estado de salud de

ción», 281). En la misma línea Solozábal Echevarría (2001, p.112) señala que «desde la interpretación de los derechos in favor libertatis y la condición de éste derecho como instrumental de la libertad de expresión impide considerar como no pacífica y por tanto anticonstitucional una reunión en la que por ejemplo se defienda la revolución, aunque no cabría la incitación a la comisión concreta de actos violentos de este carácter». También para que se califique de violenta es necesario que se trate de una situación de violencia apreciable y significativa, no localizada y accidental, jugando el principio de proporcionalidad un papel capital (SANTAMARÍA PASTOR, «El artículo 21», 418).

${ }_{18}$ STC 170/2008, de 15 de diciembre, F.J.2. 
los congregados se había degradado y las circunstancias sanitarias eran muy deficientes.

El concepto de orden público es un concepto jurídico indeterminado, que, por tanto debe ser interpretado de una manera restrictiva, favoreciendo así el ejercicio del Derecho Fundamental. En este sentido, la mayoría de la doctrina considera que el orden público a que hacen referencia los precitados preceptos, constitucional y legal, hay que entenderlo en sentido material, en tanto «limitación de un derecho por razón de tranquilidad, seguridad o salubridad pública».

Ahora bien, la alteración del orden público sin más no es suficiente para que la autoridad lo prohíba, suspenda o disuelva una reunión o manifestación. La CE y la LODR requieren que esa alteración vaya acompañada de peligro para personas y bienes. De acuerdo con la doctrina del TC en su STC 55/1990 «aun admitiendo que la alteración del orden público se produce cuando injustificadamente se limita el derecho a la libre circulación, es evidente que la norma constitucional exige también la creación de una situación de peligro que hay que estimar cumplida cuando la conducta de los manifestantes pueda inferirse determinada violencia física o, al menos, moral con alcance intimidatorio para terceros». De ahí que en los casos en los que existan razones fundadas que lleven a pensar que los límites señalados no van a ser respetados, la autoridad competente pueda exigir que la concentración se lleve a cabo de forma respetuosa con dichos límites constitucionales, o incluso, si no existe modo alguno de asegurar que el ejercicio de este derecho lo respete, puede prohibirlo.

Ahora bien, para que los poderes públicos puedan incidir y limitar el ejercicio del derecho de reunión constitucionalmente garantizado, ya sea restringiéndolo, modificando las circunstancias de su ejercicio, o prohibiéndolo incluso, es preciso, tal y como acaba de señalarse, que existan razones fundadas, lo que implica una exigencia de motivación de la resolución correspondiente en la que se aporten las razones que han llevado a la autoridad gubernativa a concluir que el ejercicio del derecho de reunión, tal y como hubo proyectado por su promotor o sus promotores, producirá una alteración del orden público proscrita en el artículo 21.2, o bien la desproporcionada perturbación de otros bienes y derechos protegidos por la $\mathrm{CE}^{19}$.

Además, no basta con que existan dudas sobre si el derecho de reunión pudiera producir efectos negativos, debiendo presidir toda actuación limitativa del mismo principio o criterio de favorecimiento del derecho de reunión (favor libertatis), de manera que sólo razones convincentes e imperativas

${ }_{19}$ Entre otras, STC 195/2003 de 27 de Octubre, FJ.4 y STC 170/2008 de 15 de Diciembre, FJ.3. 
puedan justificar la restricción a esa libertad ${ }^{20}$. De esta doctrina, se hecho especial énfasis en que el concepto de orden público con peligro para las personas y bienes del artículo 21.2 debe ser interpretado como una «situación de hecho», es decir, el orden en sentido material en los lugares de tránsito público y no como un orden sinónimo de respeto a principios y valores jurídicos y metajurídicos, puesto que el contenido de las ideas sobre las reivindicaciones que pretenden expresarse y defenderse mediante el ejercicio de este derecho no puede ser sometido a controles de oportunidad político. Por último, toda limitación del derecho de reunión, señala el TC debe ser ejercitada por los poderes públicos bajo el criterio de proporcionalidad, es decir, antes de prohibir una concentración deben proponerse modificaciones que permitan el ejercicio del derecho ${ }^{21}$.

Como consecuencia de lo dicho anteriormente las concentraciones tan sólo pueden prohibirse, dentro del concepto de orden público, en aplicación del límite previsto del artículo 21.2, cuando existe una situación de desorden material en el lugar de tránsito público, entendiendo por desorden material el que impide el normal desarrollo de la convivencia ciudadana en aspectos que afectan a la integridad física o moral de personas o la integridad de bienes públicos o privados. Estos son los dos elementos que configuran el concepto de orden público con peligro para personas y bienes consagrada en el la CE. Sólo podrá afectarse el orden público cuando el desorden externo en la calle ponga en peligro real la integridad de personas o de bienes ${ }^{22}$.

2. Los límites derivados del ejercicio de otros derechos: el caso especial de la libre circulación de personas

El ejercicio del derecho de reunión en lugares de tránsito público y manifestación impide, generalmente, el normal ejercicio de otros derechos fundamentales por parte de los ciudadanos que no participan en las mismas, fundamentalmente el derecho a la libre circulación. En este caso pues estamos ante un conflicto de derechos, que habrá de ser resuelto por los órganos jurisdiccionales mediante una adecuada ponderación, caso por caso. En concreto se ha plantada reiteradamente dicho ejercicio de ponderación de bienes en sobre el tráfico circulatorio. Para ello sigue siendo acertada la doctrina consolidad del TC en su STC 163/2006. En efecto, en el caso de las concentraciones que afectan a la circulación de vehículos por las vías de tránsito público lo primero que cabe afirmar es que sólo en supuestos muy concretos podrá concluirse que la afectación del tráfico conlleva una alteración del

\footnotetext{
20 STC 236/2007, de 7 de noviembre, FJ.6.

${ }_{21}$ STC 301/2006 de 23 de Octubre, FJ. 4

22 STC 163/2006, de 22 de mayor FJ.2.
} 
orden público. Es cierto que la paralización del tráfico con finalidad primordial de alterar la paz pública no constituye un objeto integrable en el derecho de reunión en lugares de tránsito público. Sin embargo, no es menos cierto que por su propia naturaleza el ejercicio de este derecho requiere la utilización de los lugares de tránsito público y, dadas determinadas circunstancias, permite la ocupación, por así decir, instrumental de las calzadas. En suma, la celebración de este tipo de reuniones, suele producir trastornos y restricciones en la circulación de personas y, por lo que aquí interesa, de vehículos que se ven impedidos de circular libremente por el lugar en que se celebre la reunión ${ }^{23}$. Pero el espacio urbano no es sólo un ámbito de circulación sino de participación y por ello se establece para conciliar ambos derechos la exigencia de comunicación previa al objeto de que los poderes públicos puedan adoptar las medidas preventivas necesarias para lograr es compatibilidad. Concretamente, para poder prohibir la manifestación deberá producirse la abstracción total de vías de circulación que provoquen colapsos circulatorios en los que, durante un periodo de tiempo prolongado, quede inmovilizados vehículos y se impida el acceso a determinadas zonas o barrios de la ciudad por imposibilidad de que la autoridad gubernativa habilite vías alternativas de circulación. En estos supuestos de colapso circulatorio con inmovilización e imposibilidad de acceso a determinadas zonas por inexistencia de vías alternativas, como se dijo en la STC 59/1990, puede resultar afectado el orden público con peligro para las personas o bienes si, por ejemplo, resulta imposibilitada la prestación de servicios esenciales con incidencia en la seguridad de las personas o bienes, como son los servicios de ambulancias, bomberos, policía o urgencias médicas. Para restringir el derecho de reunión del artículo 21.2 sobre el ejercicio del derecho fundamental del artículo 19 de la CE deberá ponderarse caso por caso con el fin de verificar si existen razones fundadas para creer que el colapso circulatorio tendrá las características y los efectos antes descritos ${ }^{24}$.

23 STC 59/1990, FJ.2.

${ }^{24}$ En definitiva señala el TC en su STC 163/2006 «no puede invocarse una genérica conflictividad circulatoria, ya que incluso en zonas de densa circulación, pueden darse casos en los que circunstancias específicas de las reuniones convocadas - días festivo, poca asistencia de los convocantes o la garantía de no obstrucción prolongada de calzadas- lleven a la convicción de que no existen razones fundadas de que la reunión va a producir un colapso circulatorio que altere el orden público con peligro para personas o bienes». 
3. Limites derivados de la dignidad e integridad moral de las personas

En ese sentido el TC ha puesto de manifiesto que el Derecho de reunión y manifestación no comprende la posibilidad de ejercer una violencia moral intimidatorio sobre terceros, porque ello es contrario al bien constitucionalmente protegido como la dignidad de la persona y su derecho a la integridad moral, artículos 10 y18 de la CE (STC 2/1982).

\section{Derecho de reunión versus Derecho de participación política}

Han sido recientemente nuestros tribunales de justicia y también el TC los que han observado conflictos entre el ejercicio de este derecho fundamental y los derechos de participación política. El TC ha tenido la ocasión de pronunciarse recientemente en SSTC 37 y 38/2009, ambas de 9 de febrero y 96/2010 de 15 de noviembre. En resumen, la doctrina del TC entiende que para los poderes públicos puedan incidir en el derecho de reunión constitucionalmente garantizado, restringiéndolo, modificándolo o incluso prohibiéndolo en periodo electoral es preciso que existan razones fundadas, lo implica una exigencia de motivación de la resolución en la que no bastan con que existan dudas sobre si el derecho de reunión pudiera producir efectos negativos en un proceso electoral, que aquí particularmente nos interesa, pues si bien señala el TC en sus sentencias citadas, «las opiniones derivadas de este intercambio, exposición, defensa, o reivindicación pueden llegar a influir en los ciudadanos en los procesos electorales, dicha situación sólo puede ser contemplada como una mera sospecha o una simple posibilidad. En otro caso, debe favorecerse el ejercicio del derecho de reunión aun en detrimento de otros derechos, en especial los de participación política, no sólo por significarse como un derecho esencial en la conformación de la opinión pública, sino para la necesidad de su ejercicio previo de los mencionados derechos». Por este motivo el derecho de reunión debe prevalecer, salvo que resulte suficientemente acreditado por la Administración, y, en su caso, por los Tribunales que la finalidad principal de la convocatoria es la captación de sufragios. El mero hecho de que el artículo 53.1 de la LO 5/1985 de 19 de junio de Régimen Electoral establezca que no puede difundirse propaganda electoral ni realizarse actos de campaña alguno, no impide en modo alguno que durante la jornada de reflexión no pueda celebrarse ninguna reunión o manifestación pública cuyo objeto tenga algo que ver con el debate político y, por tanto, pueda influir indirectamente en las decisiones de los electores. Teniendo en cuenta el carácter de exposición pública y colectivo de ideas, opiniones o reivindicaciones que es consustancial al ejercicio del derecho de reunión, es elemental que, por principio, toda reunión o manifestación pueda conectarse en último término, aunque sea remotamente, con el 
debate político y, por lo mismo, con las decisiones de los electores, si bien dicha hipótesis resulta insuficiente para limitar el derecho de reunión ${ }^{25}$.

5. Limites derivados del ejercicio del derecho de petición del artículo $29 \mathrm{y}$ la autonomía de las Cortes

En ese sentido, el artículo 77 de la CE prohíbe la presentación directa de peticiones a las Cámaras a través de manifestaciones ciudadanas. La prohibición afecta a las manifestaciones que preceden a la entrega a las Cámaras de una petición. Como pone de relieve Alonso de Antonio la finalidad pretendida es doble. En primer lugar se trata de proteger los alrededores de la sede de la asamblea parlamentaria. En segundo lugar, se pretende evitar la potencial coacción para los miembros de dicha asamblea por parte de quienes acuden a la manifestación. Estas manifestaciones se encuentran tipificadas en el artículo 494 del Código Penal.

6. El uso de uniformes paramilitares de los asistentes

Las reuniones en las que se haga uso de este tipo de uniformes serán suspendidas y disueltas por la autoridad gubernativa (art. 5 de la LODR). La inclusión de este límite por el legislador es consecuencia directa del mandato constitucional, según el cual toda reunión debe ser pacífica. Es bastante presumible que las reuniones en las que la mayor parte de los asistentes aparezcan ataviados con uniformes de dicho carácter tendrán por objeto la comisión de actos violentos.

\section{LAS ACTUACIONES Y PRINCIPIOS GENERALES DE LA LO 4/2015 PARA EL MANTENIMIENTO Y RESTABLECIMIENTO DE LA SEGURIDAD CIUDADANA EN REUNIONES Y MANIFESTACIONES}

Aunque en principio, la actual ley da apariencia de que se prevé la protección de la celebración de reuniones y manifestaciones, la realidad es que del análisis de su contenido se dirige a regular la disolución de las mismas y no exactamente a la protección de este derecho fundamental, pues todas las medidas que contempla están orientadas no a proteger, sino a limitar el ejercicio del mismo. Así, con respecto a la mencionada protección, se marca, como objetivo de las autoridades, no que procuren que no se perturbe la seguridad ciudadana (lo que se refleja en la LO 9/83 del 15 de julio de 1983, reguladora del derecho

${ }^{25}$ STC $96 / 2010$, F.J.4 
de reunión), sino que impidan esa perturbación, situando en primer lugar, no la protección del derecho de reunión y manifestación, sino la protección de la seguridad ciudadana, cuya interpretación queda a expensas de lo que las autoridades consideren como tal. Aunque se mantiene la posibilidad de disolver reuniones y manifestaciones en los supuestos previstos en el artículo 5 de la LO 9/1983 anteriormente citada, que regula el derecho de reunión, con la nueva ley se elimina la necesidad de realizar estas disoluciones «en la forma que menos perjudique». Como novedad, se prevé que antes de adoptar las medidas precisas para la disolución de reuniones y manifestaciones, lo agentes deberán avisar a las personas afectadas, lo que nos remitiría a la necesidad de entregar resolución motivada. Sin embargo, este deber impuesto a los agentes desaparece en la práctica cuando se incluye que el aviso se podrá hacer de manera verbal, lo que conlleva la inexistencia de control de su cumplimiento, pues bastaría con los argumentos expuestos por los agentes de autoridad para darle veracidad a los hechos, aunque no se haya producido, si la urgencia de la situación lo hiciera imprescindible, introduciendo, nuevamente, conceptos indeterminados que de dejan a la libre interpretación de los agentes, pudiendo imaginar que, en la disolución de cualquier reunión o manifestación, siempre se podrá alegar que existía una situación de urgencia.

Finalmente, introduce otra novedad que atenta gravemente contra los derechos de reunión y manifestación, pues permite a los agentes disolver dichas reuniones o manifestaciones cuando se produzca una alteración de la seguridad ciudadana, con armas, artefactos explosivos, u objetos contundentes o «de cualquier otro modo peligrosos», lo que permite de nuevo a los agentes de seguridad proceder a la disolución aun en el caso de que la alteración del orden público sea llevado a cabo por un grupo muy reducido de personas o incluso una sola y también obrando de acuerdo a la libre interpretación de los agentes, dada la indefinición de objetos que pueda servir de medio para alterar el orden público. Por ejemplo, tirar una piedra o enarbolar una bandera cualquiera podría dar lugar a la disolución de una manifestación o reunión, según lo dispuesto en el texto legal.

\section{LAS POTESTADES ESPECIALES DE POLICÍA ADMINISTRATIVA DE SEGURIDAD EN EL EJERCICIO DEL DERECHO DE REUNIÓN Y MANIFESTACIÓN Y EL NUEVO RÉGIMEN SANCIONADOR}

\section{A. Los sujetos responsables y la regulación de las nuevas infracciones muy graves}

En relación con los sujetos responsables, aparece un nuevo artículo que dispone que la responsabilidad de las infracciones cometidas recaerá 
directamente en el autor del hecho que cometa la infracción, eliminando del anterior anteproyecto la responsabilidad extensiva para todas las infracciones, pero se mantiene la definición de responsables como «organizadores o promotores de reuniones o manifestaciones», en términos similares a la anterior ley: las personas físicas o jurídicas que hayan suscrito la preceptiva comunicación, y los que, no habiendo suscrito o presentado la comunicación, de hecho las presidan, dirijan o ejerzan actos semejantes, o quienes por publicaciones o declaraciones de convocatoria de las mismas, por las manifestaciones orales o escritas que en ellas se difundan, por los lemas, banderas $\mathrm{u}$ otros signos que ostenten o por cualesquiera otros hechos pueda determinarse razonablemente que son directores o inspiradores de aquéllas. Como novedad, este artículo incluye también la exoneración de responsabilidad de los menores de 14 años.

En cuanto al catálogo de infracciones se establece una nueva clasificación de infracciones leves, graves y muy graves. Con respecto a las infracciones muy graves, es verdad que el número de las mismas baja considerablemente respecto al anterior proyecto, de 10 a 4, atenuadas, eso sí, por los dictámenes preceptivos al proyecto de ley, tanto del Consejo General del Poder Judicial, como del Consejo de Estado. Las novedades más importantes en este apartado de infracciones graves son dos, la primera, aunque desaparece como infracción muy grave, la celebración de reuniones no comunicadas en lugares de tránsito público o de manifestaciones, cuya responsabilidad corresponde a los organizadores o promotores, siempre que concurrieran una serie de requisitos agravatorios del hecho, en su lugar se califican como muy graves las reuniones o manifestaciones en áreas prohibidas que tengan las consideración de infraestructuras o instalaciones en las que se prestan servicios básicos para la comunidad o en sus inmediaciones, desconociendo hasta donde son sus inmediaciones, así como la intrusión en sus recintos, su sobrevuelo, interferencia, ilícita u obstrucción en su funcionamiento, siempre que se haya generado un riesgo para las personas o perjuicio en dicho funcionamiento. Una vez más, se comete el error de incorporar conceptos jurídicos indeterminados en materia sancionadora, lo que provoca una gran discrecionalidad y arbitrariedad en la aplicación de la normativa. Además, aquí la responsabilidad se extiende a los organizadores y promotores en sentido amplio. Se sigue equiparando en la ley el concepto de manifestación no comunicada con manifestación prohibida, cuando se trata de casos sustancialmente diferentes: en el primer caso no se ha cumplimentado un requisito formal obsoleto (la comunicación-autorización encubierta) y en el segundo caso, la autoridad gubernativa ha prohibido expresamente su celebración. Para evitar la indefinición en que incurrían los últimos anteproyectos y proyectos, las Disposición Adicional Sexta establece ahora que se entenderá por infraestructuras o instalaciones en las que se prestan servicios básicos para la 
comunidad ${ }^{26}$. En este apartado, también se incluye como infracción grave la proyección de haces de luz sobre pilotos o conductores de medios de transporte, que puedan deslumbrarles o distraer su atención y provocar un accidente. La cuantía de la multa podría llegar desde los 30.000 euros hasta los 600.000 euros, igual que en el anterior anteproyecto y la actual LPSC.

\section{B. La nueva regulación y supuestos de infracciones graves}

El eje central de la LPSC gira entorno a sancionar conductas especialmente vinculadas al ejercicio del derecho de manifestación y de reunión. Por cuanto respecta a las nuevas infracciones graves, si bien es verdad que la cantidad ha sido minimizada pasando de 31 a 16 en la actualidad ${ }^{27}$, estas nuevas infracciones son un compendio del repertorio de protesta social, plasmando una a una estas acciones y definiendo así nuevas infracciones sancionadas con multas que oscilan entre 601 a 30.000 euros:

a) La perturbación del orden en actos públicos, deportivos, culturales, espectáculos, oficios religiosos u «otras reuniones a las que asistan numerosas personas», llamado en el anterior proyecto «reuniones numerosas» (art.36.1). En el anterior proyecto se exigían que fueran perturbaciones graves, en este se elimina el calificativo de grave. De

${ }^{26}$ Según la Disposición Adicional Sexta de la LO 4/2015, de 30 de marzo (BOE N. ${ }^{\circ} 77$ de 31 de marzo del 2015), son infraestructuras o instalaciones en las que se prestan servicios básicos para la comunidad a los efectos de los dispuesto en los artículos 35.1 y 36.9 las siguientes:

a) Centrales nucleares, petroquímicas, refinerías y depósitos de combustible.

b) Puertos, aeropuertos y demás infraestructura de transporte.

c) Servicios de suministro y distribución de agua, gas y electricidad

d) Infraestructura de telecomunicaciones.

${ }^{27} \mathrm{El}$ anterior proyecto de ley incluía las siguientes infracciones graves que ahora se han eliminado de la ley actual:

- Alterar el orden público encapuchado o con cualquier elemento que dificulte la identificación.

- Perturbación del orden en campaña electoral.

- Ofensas o ultrajes a España, a las Comunidades Autónomas y entidades locales o a sus instituciones, símbolos, himnos o emblemas, efectuadas por cualquier medio.

- Manifestaciones públicas, escritas o verbales, efectuadas a través de cualquier medio de difusión, así como el uso de banderas, símbolos o emblemas para incitar comportamientos que alteren la seguridad ciudadana.

- Forzar o inducir a menores al consumo de alcohol o drogas

- El botellón, cuando perturbe gravemente la tranquilidad ciudadana y no esté autorizado. Sobre esta cuestión ya hay una ley específica que no era necesario volver a sancionar por lo mismo. 
nuevo nos encontramos con conceptos jurídicos indeterminados susceptibles de arbitrariedad de manera que bastará cualquier mínima alteración para que la autoridad gubernativa pueda sancionar o la apreciación de la misma puedan actuar las fuerzas de seguridad sobre el ejercicio del derecho fundamental de reunión, dejando la nueva ley de esta manera una vez más, un amplio poder discrecional y de actuación a los agentes encargados de velar por la seguridad ciudadana.

b) El artículo 36.2 sanciona como infracción grave las concentraciones frente al congreso de los Diputados, el Senado o las Asambleas legislativas de las Comunidades Autónomas siempre y cuando no se comuniquen previamente e independientemente estén o no estén los diputados reunidos y no constituya infracción penal. Como señala la propia norma es necesario que sea una perturbación grave (en el último proyecto se incluía solo la perturbación). Con ello se sanciona los «rodea congreso», independientemente además de que estén reunidas las Cortes, dando lo mismo si se perturba o no el normal funcionamiento y sancionando en definitiva el mero hecho de protestar. De nuevo es sintomático la finalidad de no permitir esta visibilización del malestar social ante los órganos representativos de la ciudadanía. Sin embargo, la naturaleza de determinadas reuniones implica que se desarrollen ante la sede de instituciones representativas. Como señala la STC 66/1995 de 8 de mayo, hay lugares que tienen «un relieve especial para los convocantes puesto que son condición necesaria para que las opiniones y las reivindicaciones lleguen a sus destinatarios principales».

c) Con la misma sanción se castiga los actos de obstrucción que pretendan impedir a cualquier autoridad, empleado público o corporación oficial el ejercicio legítimo de sus funciones, el cumplimiento o la ejecución de acuerdos o resoluciones administrativas o judiciales, siempre que se produzcan al margen de los procedimientos legalmente establecidos y no sean constitutivos de delito. La citada norma parece especialmente concebida para sancionar los actos de protesta contra los lanzamientos hipotecarios.

d) Otra infracción grave resulta de obstaculizar gravemente de los servicios de emergencia en el desempeño de sus funciones, matizando respecto del proyecto anterior que serán los casos en que se provoque o incremente un riesgo para la vida o integridad de las personas o daños en los bienes.

e) La desobediencia o resistencia a la autoridad o a sus agentes en el ejercicio de sus funciones, la negativa a identificarse o la alegación de datos falsos o inexactos en los procesos de identificación.

f) La negativa a disolver reuniones o manifestaciones en lugares de tránsito público cuando concurran los casos previstos en la ley para instar 
dicha disolución. Eso es novedoso respecto al anterior proyecto, que lo que sancionaba era directamente la celebración de reuniones sin previa comunicación. Las negativas a hacer algo entrarían dentro del genérico de «desobediencia»; por lo que no era necesario ya especificarlo nuevamente.

g) La perturbación del desarrollo de una reunión o manifestación lícita, cuando con constituya delito. En todas estas últimas infracciones la sanción prevista hasta 30.000 euros resulta manifiestamente desproporcionada, lo cual queda aún más acentuado si comparamos la reacción jurídica que se propone ante esta conducta con la actualmente existente en el propio Código Penal.

h) De igual modo resulta desproporcionada el castigo con la misma sanción de la falta de colaboración con las fuerzas y Cuerpos de Seguridad del Estado en la averiguación de delitos o en la prevención de acciones que puedan poner en riesgo la seguridad ciudadana en los supuestos comentados en el apartado «f»》 (art.36.15). Resulta desproporcionado dicho deber, al reclamarse una conducta activa a ciudadanos que supera los límites razonables del comportamiento exigible por parte de los poderes estatales, con una sanción en caso de incumplimiento que también resulta desmesurada.

i) Por último, en este catálogo de infracciones graves que afectan especialmente al derecho fundamental de reunión y manifestación se encuentra el uso no autorizado de imágenes o datos personales o profesionales de autoridades o miembros de las fuerzas y cuerpos de seguridad de los agentes, las instalaciones o el riesgo del éxito de la información, sin menoscabar el derecho fundamental a la información. Esta infracción es así misma contradictoria de manera que la coletilla «sin menoscabar el derecho fundamental de información» no se aplicará. A día de hoy, la persecución a los periodistas, fotógrafos o streamer, y a todo aquel que saque un móvil para grabar una intervención legal, es muy elevada, con esta previsión los agentes tienen la excusa para ponerte una multa, y le tocará al ciudadano agotar la vía administrativa y en su caso previo pago de tasas recurrirla judicialmente.

\section{El nuevo catálogo de infracciones leves}

No menos problemático resulta el nuevo catálogo de infracciones leves que al igual que en el resto de infracciones se han reducido ${ }^{28}$ en la ley actual

${ }^{28}$ En el anterior anteproyecto se incluían las siguientes infracciones que ahora se han eliminado.

- La colocación de tiendas de campaña o tenderetes sin permiso en la calle. 
y lo que es más importante la multa o sanción ha pasado del anterior anteproyecto entre 1001 y 30.000 euros al actual 100 a 600 euros lo que evidenciaba el principal objetivo de la ley al restringir este derecho fundamental: su carácter disuasorio. Entre las conductas reguladas como infracciones leves más relevantes que afectan especialmente al ejercicio del derecho de reunión y manifestación caben señalar las siguientes:

a) Las manifestaciones y reuniones no comunicadas, correspondiendo su responsabilidad a los promotores. En el último anteproyecto se incluía como infracción grave la celebración de reuniones y manifestaciones no comunicadas y la negativa a su disolución, en la actual ley se incluye la negativa a su disolución como grave y la celebración sin comunicar como leve incumpliendo los preceptuado en los artículos 4.2, 8, 9, 10 y 11 de la LO 9/1983 de 15 de julio pero en todo caso la responsabilidad corresponderá a los organizadores y promotores.

b) Incumplir restricciones de circulación peatonal o itinerario con ocasión de un acto público, reunión o manifestación, cuando provoquen alteraciones menores en su normal desarrollo. Concepto ambiguo: «alteraciones menores», a valorar por los agentes en cada caso, dejando un amplio margen de discrecionalidad que puede derivar fácilmente en una actuación arbitraria.

c) Las faltas de respeto y consideración que realizan las Fuerzas y Cuerpos de seguridad en el ejercicio de sus funciones. En el anterior anteproyecto abarcaba las manifestaciones a través de cualquier medio de difusión. En el último proyecto las faltas de respeto o consideración sancionable se extiende a cualquier momento.

d) Especialmente relevante en la ley actual ha sido tipificar como infracción leve la ocupación de cualquier inmueble contra la voluntad de su propietario. Eso es nuevo y de graves consecuencias, pues el último anteproyecto no se refería a inmuebles o viviendas sino solo a espacios comunes. Se sanciona con ello la ocupación pacífica de inmuebles, en donde además del proceso judicial de las personas que resulten imputados se podrán sancionar a aquellos ciudadanos que ocupen pacíficamente un centro social, comercial o financiero con el mero fin de realizar una protesta hasta incluso simpática como pudiera ser cantar dentro de una oficina bancaria.

e) Así mismo se castiga igualmente escalar a edificios o monumentos o lanzarse sobre ellos. En la ley actual se elimina la infracción grave y

- Entorpecer la circulación peatonal.

- Prácticas de juegos o deportes en lugares no habilitados cuando haya riesgo para las personas o bienes. 
la leve abarcará todo tipos escalamiento, aunque se exige que exista un riesgo cierto de que se ocasionen daños a las personas o a los bienes.

f) Otras infracciones menores son retirar las vallas de la policía que delimitan los perímetros de seguridad, los daños o el deslucimiento de bienes inmuebles de uso o servicio público, así como de bienes muebles o inmuebles privados en la vía pública, cuando no constituyan infracción penal o la proyección de haces de luz, mediante, mediante cualquier tipo de dispositivo sobre miembros de las fuerzas y cuerpos de seguridad para impedir o dificultar el ejercicio de sus funciones.

\section{CONCLUSIONES}

El nuevo texto aprobado de la LPSC contrasta claramente con la doctrina del Tribunal Constitucional que de manera clara y directa ha desarrollado como se ejerce el derecho fundamental de reunión y manifestación, con atribuciones en materias de protección del orden público y la seguridad ciudadana más orientada a regular las facultades de policía e intervención administrativa de la autoridad que garantizar el ejercicio del derecho de reunión y manifestación. El origen de esta ley tiene su origen en las tensiones existentes ante el desmantelamiento del Estado Social. Ello está convirtiendo el descontento y el conflicto social en un asunto de orden público, por una gestión inadecuada de la pluralidad democrática por parte del poder ejecutivo con reformas que como esta suponen el mayor atentado al Estado democrático de toda la etapa democrática, limitando especialmente el derecho de manifestación, el derecho de reunión, el derecho a la información y los derechos fundamentales a la libertad de expresión y el derecho de huelga.

La reforma incluye un incremento desproporcionado de las infracciones existentes en materia de orden público. Estas nuevas conductas resultan especialmente molestas al poder político, como las movilizaciones de distintos colectivos sociales, la ocupación pacífica de entidades bancarias o la convocatoria de manifestaciones y concentraciones a través de las redes sociales. Sin embargo, en una sociedad plural resulta positivo que se puedan expresar los diferentes puntos de vista que la conforman, siempre y cuando no se causen daños a personas o bienes, pues como señaló la STC 9/2007 «en una sociedad democrática el espacio urbano no es sólo un ámbito de circulación, sino también de un ámbito de participación».

A lo largo de todo el articulado se detecta la reiteración administrativa en la tipificación de conductas que ya estaban en el Código Penal como determinadas modalidades de desórdenes públicos o la propia desobediencia no introduciéndose ninguna alusión sobre la aplicación del principio constitucional «non bis in Idem». Con dicha redundancia se aprecia una 
clara voluntad de extraer del análisis judicial determinadas conductas muy vinculadas al ejercicio de derechos fundamentales como el derecho de manifestación, el derecho de reunión o la libertad de expresión. Resulta necesario recordar, que han sido nuestros propios jueces y tribunales los que han considerado que no existía infracción penal en determinadas manifestaciones o reuniones ante edificios oficiales, ni tampoco de los denominados escraches cuando se han desarrollado pacíficamente, ni en diversas actuaciones de protesta contra los desalojos hipotecarios. En consecuencia, la reforma del derecho administrativo sancionador, se inspira en una clara desconfianza en la actuación del poder judicial, por no haber satisfecho las exigencias punitivas del poder político. Resulta preocupante que dichas materias, vinculadas al ejercicio de derechos fundamentales, no sean analizados por órganos independientes e imparciales, sino por una administración pública que tiene un interés directo en los conflictos objeto de dichos procedimientos.

La amplitud fáctica de las nuevas normas y la discrecionalidad en la valoración de las conductas sancionables administrativamente provocarán un incremento del margen de actuación policial que atenta contra el principio constitucional de la proporcionalidad en sentido estricto. Es decir, el balance de costes y beneficios en lo que respecta a los derechos y valores constitucionalmente protegidos que se encuentran involucrados. En efecto, la ampliación del margen de discrecionalidad de los agentes estatales en la adopción de medidas que puedan restringir el derecho de reunión y asociación evidentemente se traduce en un coste para su libre ejercicio que no aparece equilibrado con claridad por los beneficios concretos a la actual situación de orden público. En cuanto la necesidad en términos de proporcionalidad de estas medidas la jurisprudencia del TC en su sentencia 301/2006 de 23 de octubre resulta clara: «....reiteradamente este Tribunal se ha referido a que toda limitación del derecho de reunión debe ser ejercitada por los poderes públicos bajo el criterio de la proporcionalidad, es decir, antes de prohibir una concentración deben proponerse modificaciones que permitan el ejercicio del derecho».

La aplicación de esta nueva ley, si bien como ya hemos señalado ha sido muy suavizada tras los dictámenes que del Consejo del Poder Judicial y del Consejo de Estado que la tachaban de inconstitucional, generará con todo un efecto disuasorio y de desaliento en el ejercicio de los derechos fundamentales, ante el riesgo de que eventuales circunstancias puedan provocar en el marco de una manifestación o de una reunión, la privación de libertad o la insolvencia económica. En definitiva, la citada reforma supone el mayor impacto negativo en nuestro Estado Democrático al erosionar gravemente el ejercicio de los derechos fundamentales de clara raíz política y democrática como son el derecho de reunión, manifestación y expresión. 
TITLE: The right of meeting and demonstration in the new regulatory framework of the citizen security protection Act of 4/2015 of March 30

RESUMEN: El presente trabajo de investigación tiene como objeto el estudio, incidencia y limitaciones que ha suscitado la reciente aprobación de Protección de Seguridad Ciudadana LO 4/2015 de 30 de marzo, en concreto en aquellas medidas que afectan al ejercicio del derecho fundamental de reunión y manifestación y a todo un modelo de Estado Social y Democrático de derecho que está siendo amenazada con la presente crisis económica y social. La realidad de esta norma surge en un contexto de evidentes tensiones sociales cuyo descontento social antes las crisis y los recortes sociales se está canalizando hacia las más variadas formas de protestas, lo que ha supuesto con esta reforma restringir uno de sus derechos más básicos como es el derecho a la manifestación. La aplicación de esta ley ha supuesto regular un conjunto de medidas que afectan a la dimensión constitucional de este derecho y especialmente de su contenido esencial, lo que se traduce a nuestro juicio desde el análisis más concreto de la doctrina del Tribunal constitucional como una intervención legislativa inconstitucional y en un coste antidemocrático para los ciudadanos en el ejercicio de sus derechos y libertades. A pesar de que la ley afecta a un gran contenido de medidas de seguridad ciudadana me centraré en este artículo en aquellas que afectan o inciden el ejercicio democrático del derecho fundamental de reunión y manifestación.

PALABRAS ClaVE: Derechos fundamentales, Derecho de Reunión, Manifestaciones Públicas, participación política, libertad de expresión. Derecho democrático. Ley mordaza. Tipos de reuniones. Orden Público. Seguridad ciudadana.

ABSTRACT: The object of the present research is the study of incidence and limitations that has raised the recent approval of Citizen Security Protection LO 4/2015 of $30^{\text {th }}$ of March, specifically in those measures that affect the exercise of the fundamental right of Assembly and Demonstration, and to a whole model of Social and Democratic State of law, which is being threatened with the current economic and social crisis. The reality of this norm arises in a context of obvious social tensions whose social discontent against the crises and the social cuts is being channeled towards the most varied forms of protest, that with this reform has supposed to restrict one of its most basic rights as it is the right to demonstrate. The application of this law has meant regulate a set of measures which affect the constitutional dimension of this right and especially its essential content, that translates in our view, from the most concrete analysis of the doctrine of the Constitutional Court, as an unconstitutional legislative intervention and at an undemocratic cost to citizens in the exercise of their rights and freedoms. Although the law affects a large number of citizen security measures, on this article I will focus in those that affect or influence the democratic exercise of the fundamental right of Assembly and Demonstration. 
KEY WORDS: Fundamental Rights, Right of Assembly, Public Demonstrations, Political Participation, Freedom of Speech, Democratic law, «Jaw law» (Ley mordaza), Types of Assembly, Public order. Citizen security.

RECIBIDO: 18.04 .2016

ACEPTADO: 19.12 .2016 